of methods of determination of vapour pressure and equilibrium compositions, one feels that the authors would have much to contribute on the special problems connected with thermostats. Many readers will be grateful for the extensive review of equilibrium stills, particularly because of the systematic method of classification employed, and the summarized comparison of them in a single table at the end of the chapter.

Part 3 consists of an alphabotical index to more than 1,200 references to original work on the experimental determination of equilibrium data. This impressive list is all the more valuable as it gives world-wide coverage of technical publications up to February 1957.

Although the book falls short of a comprehensive treatise and in its present edition has a number of shortcomings, it is nevertheless an outstanding contribution to the subject, and contains so much of solid worth that most workers in the field should learn something from its pages, and find it of constant value as a reference work.

R. SARGENT

\section{TRANSISTOR ELECTRONICS}

\section{Junction Transistor Electronics}

By Richard B. Hurley. Pp. xvii +473. (New York: John Wiley and Sons, Inc.; London : Chapman and Hall, Ltd., 1958.) 100s. net.

\section{Transistor Electronics}

By Arthur W. Lo, Richard O. Endres, Jakob Zawels, Fred D. Waldhauer and Chung-Chih Cheng. Pp. xii +521. (London: Macmillan and Co., Ltd., 1958.) 45s. net.

N its own Hurley's book has a certain amount to commend : it is, however, difficult to understand the publishing policy of Messrs. John Wiley and Sons. About a year ago they published an excellent work on junction transistors edited by R. F. Shea, a book which received very favourable reviews. Hurley covers much the same ground as Shea, differing only in detail, and although I must admit his book is possibly designed more for use as a text-book, it cannot help being a competitor to Shea's work.

Introductory chapters on semi-conductor principles lead on to the small signal equivalent eircuit of the transistor and the use of this circuit in the analysis of the transistor audio-amplifier. A chapter is devoted to bias stabilization and another to the application of negative feedback. The subject-matter of Chapter 6, "The Nature of Internal Noise Genera. tion and Its Outward Effects", receives much better treatment than in Shea's book where it was dismissed, rather perfunctorily, in about a page.

The performance of a transistor under large signal conditions is considered and this leads to the problems of the design of power amplifiers. Direct-current amplifiers, video amplifiers, tuned amplifiers, automatic gain control, sinusoidal oscillators, modulation circuits all receive attention by way of separate chapters. Three more chapters deal with transistors in switching applications and in their use as relaxation oscillators.

Two rather special applications of the transistor, namely, in regulated power-supplies and saturable reactor-circuits, have individual chapters and receive a more detailed treatment than in Shea's work.
As a book for reference it suffers from the absence of a list of symbols, and what is more serious, although the author himself admits it, is the use of the same symbol with entirely different, and different shades of, meaning.

The presentation and reproduction is, of course, up to John Wiley's usual high standard.

The work on "Transistor Electronics" by Lo et al. is a reprint of a well-known book published in 1955 in the United States by Prentice-Hall. It has now been published in Britain by Macmillan, but the printing was carried out (and very well, too) in the Netherlands. So far as I can see there are no alterations to the original text. It covers substantially the same ground as Hurley's book but of course Hurley has three extra years development to include, and in a field that is subject to continual metamorphosis this gives him a considerable advantage.

The authors, who were all with the Radio Corporation of America when the book was written, favour the four-terminal network approach to the transistor equivalent circuit and deduce the performance in the various circuits using this as the basis. A very useful table shows the many varied forms the fourterminal equivalent network can take and will be very useful for reference. The book is intended both as a text-book for students of this subject and as a reference work, but I feel that it is in the former application that it will be most useful.

\section{J. W. R. Griffiths}

\section{PROGRESS IN PHYSIOLOGY}

\section{Annual Review of Physiology}

Vol. 21. Edited by Victor E. Hall, in association with Frederick A. Fuhrman and Arthur C. Giese. Pp. viii +636. (Palo Alto, Calif. : Annual Reviews, Inc.; and the American Physiological Society, 1959. On sale by Annual Reviews, Inc.) 7 dollars.

WITH the publication of Vol. 21, the "Annual Review of Physiology" comes of age, though it is still a mere fledgling to its 28-year sister publication, the "Annual Review of Biochemistry". Its growth over the years might be considered unphysiological, for its size at birth (705 pages) was greater than it is now (636 pages). The editorial committees have prevented the volume from becoming unmanageably large, but the question they raised last year remains unanswered: whether the present policy of "skim. ming one volumeful of physiological cream" can be continued indefinitely. With the growing output of research, it means that a progressively smaller proportion of the total published work is reviewed year by year. A similar problem exists for annual reviews in other subjects. Those who write the reviews are faced with the difficulty of selection. If they include too many papers in their survey, they tend to produce little more than an annotated card index, useful for reference but almost impossible to read through. If they select some of the more important recent work in their subject and give themselves room to discuss it, they produce a more interesting and stimulating review but may leave out a good deal of significant research. On the whole, the present reviewers have managed to make their summaries interesting to read and useful for reference.

The prefatory chapter is by A. V. Hill and deals with the heat production in muscle and nerve from 